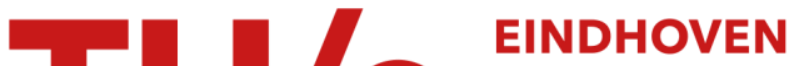 UNIVERSITY OF TECHNOLOGY
}

\section{Intermolecular effects on the radiogenic formation of electron- capture phosphorus-centered radicals. A single-crystal ESR study of diastereoisomeric precursors}

\author{
Citation for published version (APA): \\ Aagaard, O. M., Janssen, R. A. J., Waal, de, B. F. M., \& Buck, H. M. (1990). Intermolecular effects on the \\ radiogenic formation of electron-capture phosphorus-centered radicals. A single-crystal ESR study of \\ diastereoisomeric precursors. Journal of the American Chemical Society, 112(3), 938-944. \\ https://doi.org/10.1021/ja00159a005
}

DOI:

10.1021/ja00159a005

Document status and date:

Published: 01/01/1990

\section{Document Version:}

Publisher's PDF, also known as Version of Record (includes final page, issue and volume numbers)

\section{Please check the document version of this publication:}

- A submitted manuscript is the version of the article upon submission and before peer-review. There can be important differences between the submitted version and the official published version of record. People interested in the research are advised to contact the author for the final version of the publication, or visit the DOI to the publisher's website.

- The final author version and the galley proof are versions of the publication after peer review.

- The final published version features the final layout of the paper including the volume, issue and page numbers.

Link to publication

\footnotetext{
General rights

- You may freely distribute the URL identifying the publication in the public portal. follow below link for the End User Agreement:

www.tue.nl/taverne

\section{Take down policy}

If you believe that this document breaches copyright please contact us at:

openaccess@tue.nl

providing details and we will investigate your claim.
}

Copyright and moral rights for the publications made accessible in the public portal are retained by the authors and/or other copyright owners and it is a condition of accessing publications that users recognise and abide by the legal requirements associated with these rights.

- Users may download and print one copy of any publication from the public portal for the purpose of private study or research.

- You may not further distribute the material or use it for any profit-making activity or commercial gain

If the publication is distributed under the terms of Article $25 \mathrm{fa}$ of the Dutch Copyright Act, indicated by the "Taverne" license above, please 


\title{
Intermolecular Effects on the Radiogenic Formation of Electron-Capture Phosphorus-Centered Radicals. A Single-Crystal ESR Study of Diastereoisomeric Precursors
}

\author{
Olav M. Aagaard, ${ }^{*}$ René A. J. Janssen, Bas F. M. de Waal, and Henk M. Buck \\ Contribution from the Department of Organic Chemistry, Eindhoven University of Technology. \\ P.O. Box 513, 5600 MB Eindhoven. The Netherlands. Received May 31, 1989
}

\begin{abstract}
ESR experiments on X-irradiated single crystals of the $2 R, 4 S, 5 R$ and $2 S, 4 S, 5 R$ diastereoisomers of 2-chloro3,4-dimethyl-5-phenyl-1,3,2-oxazaphospholidine 2-sulfide reveal that the yield of radiogenic electron-capture reactions in the solid state strongly depends on intermolecular interactions in the crystal. In the present case a high yield of $\mathrm{P}-\mathrm{Cl}$ three-electron-bond phosphoranyl radical anions is found in crystals of the $2 R, 4 S, 5 R$ isomer, whereas no radical formation can be detected for the $2 S, 4 S, 5 R$ isomer. An analysis of nonbonded interactions with neighboring molecules reveals that the geometry relaxation necessary for the radical stabilization is easily accommodated in crystals of the $2 R, 4 S, 5 R$ isomer but not in the $2 S, 4 S, 5 R$ isomer, explaining the observed difference in electron-capture efficiency. Experiments on radical formation in a MeTHF host matrix give further insight into the importance of the environment on radiogenic radical formation. The possible concurrent effect of the matrix on the electronic configuration and spin density distribution of the resulting phosphoranyl radical is discussed.
\end{abstract}

The radiogenic formation of phosphorus-centered radicals has been extensively studied over the last decades. ${ }^{1}$ The continuing interest in phosphorus-centered radicals originates partly from their possible role in the radiation chemistry of nucleic acids and is partly a consequence of their interesting electronic, structural, and dynamical properties. It has been established that the radical configuration, formed as a result of the electron-addition process, strongly depends on the nature of the substituents linked to the central phosphorus atom. ${ }^{2}$ Recently, however, it has become clear that other effects, which are not generally taken into account, can also be decisive for the nature of the observed radiation products. In particular we reported on the pronounced differences observed in electron capture of rac- and meso-1,2-dimethyl-1,2-diphenyldiphosphine disulfide, demonstrating the importance of stereochemical effects. ${ }^{3}$ Simultaneously, Cattani-Lorente et al. showed, by studying the electron capture of 1,2-phenylene phosphorochloridate in the pure compound and in frozen solutions, that the environment of the precursor molecule influences the resulting radical configuration after $\mathrm{X}$-irradiation. ${ }^{4}$

In this paper we examine the influence of the surrounding matrix by studying radical formation in single crystals of two diastereoisomeric compounds, $(2 R, 4 S, 5 R)$ - and $(2 S, 4 S, 5 R)-2$ chloro-3,4-dimethyl-5-phenyl-1,3,2-oxazaphospholidine 2-sulfide (1 and 2)
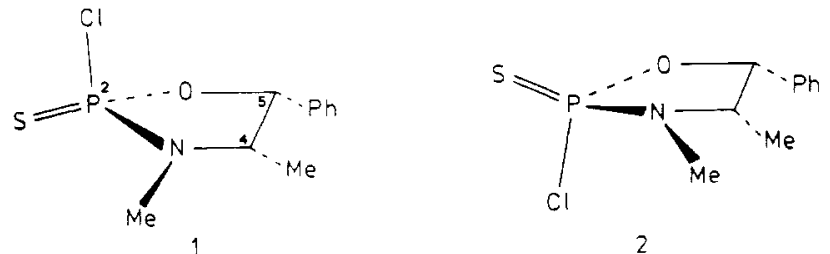

These two compounds differ by the configuration of the central phosphorus atom, while the chiral centers on $C(4)$ and $C(5)$ are identical. This introduces a difference in the crystal structures, which mimics the effect of a changing matrix. Possible intrinsic different electron-accepting properties are minimized when the chiral centers are sufficiently apart. The use of diastereoisomeric compounds in the study of matrix effects has an important ad-

(1) Bentrude, W. G. Acc. Chem. Res, 1982, 15,117

(2) For a recent compilation of data, see: Tordo, P. Landolt-Börnstein, New Series; Springer-Verlag: Berlin, 1988; Vol. II 17/e, p 254, and references cited therein.

(3) Janssen, R. A. J.; van der Woerd, M. J.; Aagaard, O. M.; Buck, H. M. J. Am. Chem. Soc. 1988, 110,6001.

(4) Cattani-Lorente, M.; Bernardinelli, G.; Geoffroy, M. Helv. Chim. Acto 1987, 70,1897 vantage over frozen solutions because, unlike in a randomly oriented glassy matrix, the microenvironment can be accurately accessed via $\mathrm{X}$-ray crystallographic analyses.

It will be shown that 1 and 2 behave very differently toward low-temperature $\mathrm{X}$-irradiation, especially concerning the yield of electron-capture radicals. A detailed analysis of the crystallographic structural data ${ }^{5,6}$ reveals that this difference is a consequence of nonbonded interactions modulating the geometry relaxation that accompanies the stabilization of the initial electron-capture radical product.

\section{Experimental Section}

$\mathbf{X}$-irradiation and ESR. Single crystals were mounted on a quartz rod and subsequently sealed in a quartz tube. The quartz tubes containing single crystals, powdered samples, or frozen solutions were X-irradiated in a glass Dewar vessel containing liquid nitrogen $(77 \mathrm{~K})$ with unfiltered radiation from a Cu source operating at $40 \mathrm{kV}$ and $20 \mathrm{~mA}$ for approximately $6 \mathrm{~h}$. ESR spectra were recorded on a Bruker ER 200D spectrometer, operating with an X-band standard cavity and interfaced with a Bruker Aspect 3000 data system. In a typical run a sweep width of $0.1875 \mathrm{~T}$ was sampled with $4 \mathrm{~K}$ points, resulting in a resolution of 0.045 $\mathrm{mT}$. The single crystals were rotated perpendicular to the magnetic field, in $10^{\circ}$ steps, by using a single-axis goniometer. Temperature was controlled with the aid of a Bruker ER 4111 variable-temperature unit. Photobleaching experiments were performed using a Philips SP 500-W high-pressure $\mathrm{Hg}$ vapor lamp. The beam was focused on the sample in the microwave cavity.

Spectral Analysis. The single-crystal ESR spectra were analyzed by use of a computer program that calculates the spin Hamiltonian parameters from the angular dependence of the resonant fields. For the radicals studied, the spin Hamiltonian consists of Zeeman, hyperfine, and nuclear Zeeman parts of orthorhombic symmetry and noncoaxial orientation of $\mathbf{g}$ and $\mathbf{A}$. The resonant fields were calculated via an exact diagonalization of the Hamiltonian.

Synthesis. $\quad(2 R, 4 S, 5 R)$ - and $(2 S, 4 S, 5 R)$-2-chloro-3,4-dimethyl-5phenyl-1,3,2-oxazaphospholidine 2-sulfide (1 and 2) were synthesized according to the method described by Lesiak et al. ${ }^{7}$ The pure diastereoisomeric compounds were obtained after chromatography of the crude reaction product on a silica-60 gel column. A mixture of $n$-hexane and diethyl ether $(75: 25 \mathrm{v} / \mathrm{v})$ was used as eluent. The compounds $1\left(R_{f}=\right.$ $0.20)$ and $2\left(R_{f}=0.15\right)$ were obtained as viscous oils. Single crystals were obtained after several recrystallizations from $n$-hexane at $4{ }^{\circ} \mathrm{C}$. 1 : ${ }^{31} \mathrm{P}$ NMR $\left(\mathrm{CDCl}_{3}\right) \delta 80.8$; ' $\mathrm{H} \mathrm{NMR}\left(\mathrm{CDCl}_{3}\right) \delta 0.80\left(3 \mathrm{H}, \mathrm{d}, \mathrm{CCH}_{3}\right)$, $2.73\left(3 \mathrm{H}, \mathrm{d}, \mathrm{NCH}_{3},{ }^{3} J_{\mathrm{PNCH}}=16.7 \mathrm{~Hz}\right), 3.75\left(1 \mathrm{H}, \mathrm{ddq}, \mathrm{C}(4) \mathrm{H},{ }^{3} J_{\mathrm{PNCH}}\right.$ $=13.1 \mathrm{~Hz}), 5.60\left(1 \mathrm{H}, \mathrm{dd}, \mathrm{C}(5) \mathrm{H},{ }^{3} J_{\mathrm{POCH}}=7.2 \mathrm{~Hz}\right), 7.30-7.44(5 \mathrm{H}$, $\mathrm{m}, \mathrm{PhH}) ; \mathrm{mp} 58{ }^{\circ} \mathrm{C} .2:{ }^{31} \mathrm{P} \mathrm{NMR}\left(\mathrm{CDCl}_{3}\right) \delta 75.9 ;{ }^{1} \mathrm{H}$ NMR $\left(\mathrm{CDCl}_{3}\right)$ $\delta 0.88\left(3 \mathrm{H}, \mathrm{d}, \mathrm{CCH}_{3}\right), 2.92\left(3 \mathrm{H}, \mathrm{d}, \mathrm{NCH}_{3},{ }^{3} J_{\mathrm{PNCH}}=14.7 \mathrm{~Hz}\right), 3.84$

(5) Bartczak, T.; Galdecki, Z.; Rutkowska, M. Acta Crystallogr. 1983. C39, 222.

(6) Bartczak, T.; Galdecki, Z. Acta Crystallogr. 1983, C39, 219

(7) Lesiak, K.; Stec, W. J. Z. Naturforsch., B 1978, 33, 782. 

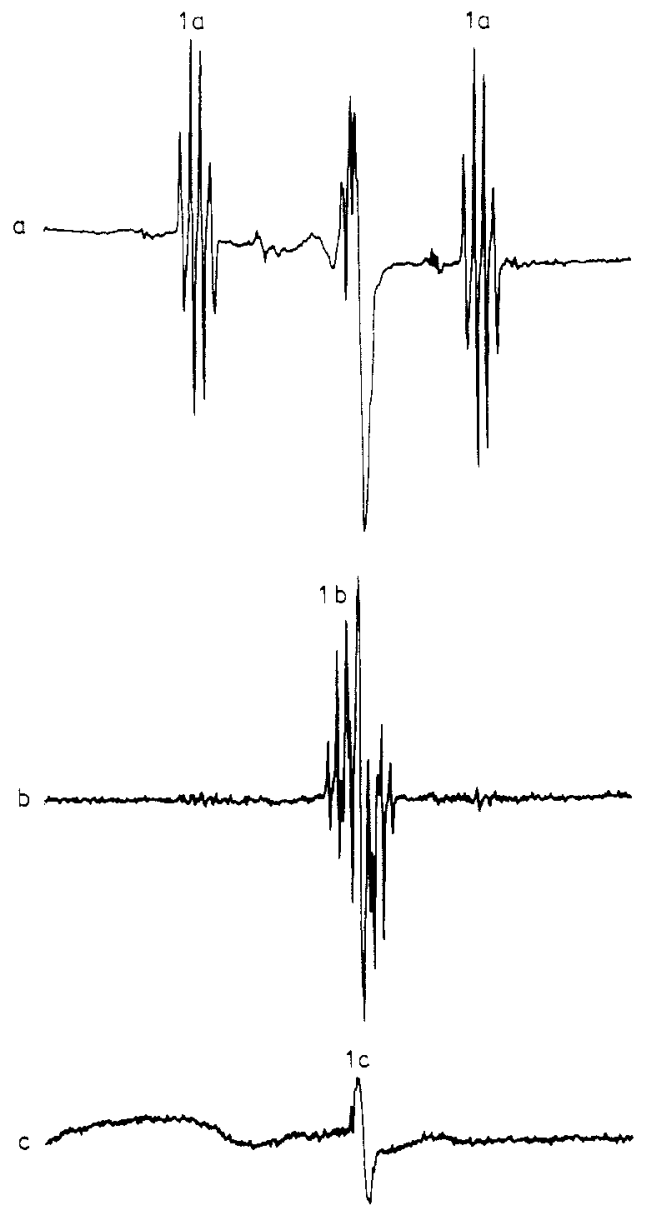

$10 \mathrm{mT}$

Figure 1. Single-crystal ESR spectra of the $\mathrm{X}$-irradiated $2 R, 4 S, 5 R$ isomer 1: (a) at $105 \mathrm{~K}$; (b) at $105 \mathrm{~K}$ after UV bleaching for $1 \mathrm{~min}$; (c) at $105 \mathrm{~K}$ after annealing to $225 \mathrm{~K}$.

$\left(1 \mathrm{H}, \mathrm{ddq}, \mathrm{C}(4) \mathrm{H},{ }^{3} J_{\mathrm{PNCH}}=28.9 \mathrm{~Hz}\right), 5.83\left(1 \mathrm{H}, \mathrm{dd}, \mathrm{C}(5) \mathrm{H},{ }^{3} J_{\mathrm{POCH}}=\right.$ $0.7 \mathrm{~Hz}), 7.29-7.48(5 \mathrm{H}, \mathrm{m}, \mathrm{PhH}) ; \mathrm{mp} 130^{\circ} \mathrm{C}$.

\section{Results}

Radical Formation in the Pure Compounds. The ESR spectrum of the $2 R, 4 S, 5 R$ isomer (1), recorded at $105 \mathrm{~K}$ after $\mathrm{X}$-irradiation at $77 \mathrm{~K}$, is shown in Figure la. The spectrum consists of three groups of lines. The low- and high-field absorptions are due to a radical, labeled 1a, exhibiting hyperfine coupling to both a ${ }^{31} \mathrm{P}$ and ${ }^{35} \mathrm{Cl}$ or ${ }^{37} \mathrm{Cl}$ isotope. On the basis of the large ${ }^{31} \mathrm{P}$ hyperfine coupling, radical la is assigned to an electron-capture phosphoranyl radical. The central absorptions, which also appear in the ESR spectrum (Figure 1a), result from the superimposed spectra of two other radical products, marked $\mathbf{1 b}$ and $\mathbf{1 c}$. The individual absorptions of $\mathbf{1 b}$ and $\mathbf{1 c}$ were readily obtained by selective UV photobleaching and temperature-resolved ESR methods, respectively. First, UV-irradiation of the single crystal, inside the microwave cavity, for $1 \mathrm{~min}$ using a high-pressure $\mathrm{Hg}$ vapor lamp leads, besides the loss of the lateral signals 1a, to an enhanced resolution of the central hyperfine pattern assigned to $\mathbf{1 b}$ as a consequence of the loss of $1 \mathbf{c}$ (Figure 1b). Alternatively, in a second experiment, the spectrum of $\mathbf{1 c}$ is obtained via slow annealing of the crystal to $225 \mathrm{~K}$, which results in the irreversible loss of both $\mathbf{1 a}$ and $\mathbf{1 b}$. Radicals $\mathbf{1 b}$ and $\mathbf{1 c}$ are assigned to electron loss and aromatic anion centers, respectively.

In sharp contrast to the high yield and corresponding strong ESR absorptions established upon X-irradiation of $1, \mathrm{X}$-irradiation of a single crystal of the $2 S, 4 S, 5 R$ isomer (2) results in a very weak ESR spectrum. The spectrum shown in Figure 2a shows only a single weak central absorption but displays virtually no signals in the lateral regions. Only after $\mathrm{X}$-irradiation of a large powdered sample of $\mathbf{2}$ can the very weak features of an elec-
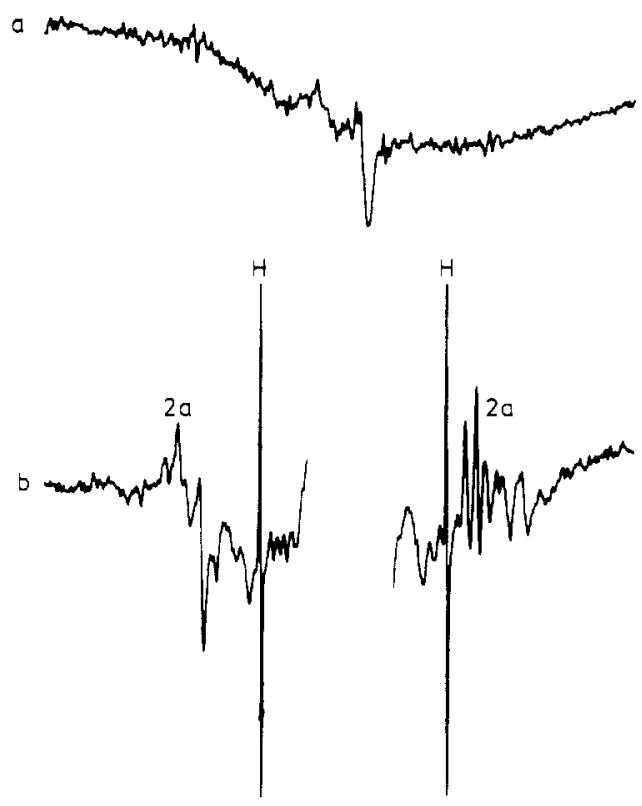

$10 \mathrm{mT}$

Figure 2. ESR spectra of the $\mathrm{X}$-irradiated $2 S, 4 S, 5 R$ isomer 2: (a) single crystal at $105 \mathrm{~K} ;$ (b) powdered sample at $105 \mathrm{~K}$, lines marked $\mathrm{H}$ result from trapped hydrogen atoms in quartz tube.

tron-capture phosphoranyl radical (2) be dectected (Figure $2 b$ ). The extra couplings discernable on the low- and high-field ${ }^{31} \mathrm{P}$ manifolds are attributed to ${ }^{35} \mathrm{Cl}$ and ${ }^{37} \mathrm{Cl}$ couplings.

It is important to note that the ESR spectra of 1 and 2 shown in Figures $1 \mathrm{a}$ and $2 \mathrm{a}$ were recorded for single crystals of approximately the same weight and same irradiation time. Hence, Figures $1 \mathrm{a}$ and $2 \mathrm{a}$ clearly demonstrate the different efficiency of the radiation-induced electron-capture process.

Single-Crystal ESR Analysis. In order to obtain a detailed description of radical 1a, we performed a single-crystal ESR analysis. In this way it is possible to obtain accurate hyperfine coupling tensors that give information on the amount of spin density on the various nuclei. Moreover, since the $\mathrm{X}$-ray crystallographic analysis of 1 has been reported, it is possible to relate the principal directions of the magnetic tensors mutually and to the molecular coordinates.

Compound 1 crystallizes in the orthorhombic space group $P 2_{1} 2_{1} 2_{1}$ with four molecules in the unit cell at special orientations $(x, y, z),(\bar{x}, 1 / 2+y, 1 / 2-z),(1 / 2-x, \bar{y}, 1 / 2+z)$, and $(1 / 2+$ $x, 1 / 2-y, \bar{z}) .^{5} \mathrm{X}$-irradiated single crystals of 1 were rotated in the three perpendicular crystallographic planes with respect to the direction of the magnetic field. The angular variation of the observed ESR transitions is depicted in Figure 3. As a consequence of the internal symmetry of the unit cell and the perpendicular orientation of the magnetic field relative to the rotation axis, the spectra of the four molecules coalesce into two observable sites. For orientations where the magnetic field exactly parallels one of the crystallographic axes, all four sites become magnetically equivalent and the ESR spectrum reduces to a simple eight-line pattern (Figure 1a). The spectra were analyzed by using the following Hamiltonian, 8,9

$$
H=\beta \mathbf{S} \cdot \mathbf{g} \cdot \mathbf{B}-g_{\mathrm{P}} \beta_{\mathrm{N}} \mathbf{I}_{\mathrm{P}} \cdot \mathbf{B}-g_{\mathrm{Cl}} \beta_{\mathrm{N}} \mathbf{I}_{\mathrm{Cl}} \cdot \mathbf{B}+\mathbf{S} \cdot \mathbf{A}_{\mathrm{P}} \cdot \mathbf{I}_{\mathbf{P}}+\mathbf{S} \cdot \mathbf{A}_{\mathrm{Cl}} \cdot \mathbf{I}_{\mathrm{Cl}}
$$

(8) Weltner, W. Magnetic Atoms and Molecules; Scientific and Academic Editions: New York, 1983.

(9) In principle there exists an ambiguity in the matching of the curves shown in Figure 3. Therefore it is possible to obtain eight different sets of $\mathrm{g}$ and $\mathrm{A}$ tensors. The eight sets can easily be separated into two classes of four tensors with mutually equivalent principal values but different direction cosines. Only one of the two sets of four tensors correponds to the righthanded coordinate system used in the single-crystal ESR analysis. These four remaining tensors correspond to the four differently oriented parent molecules in the unit cell, and hence all ambiguity in the matching of the curves is resolved. 

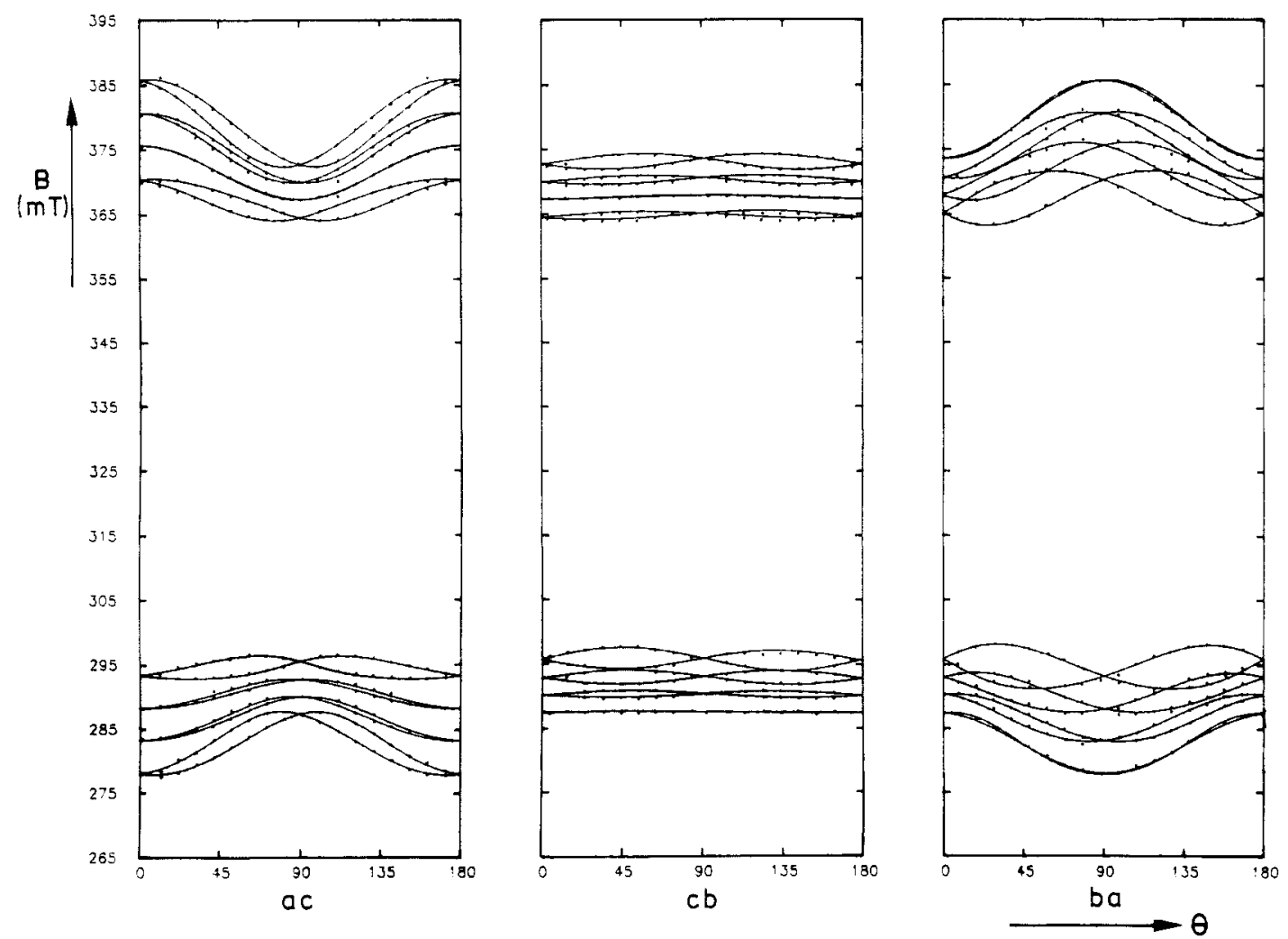

Figure 3. Angular variation of the resonant fields in single crystals of the $2 R, 4 S, 5 R$ isomer 1 for radical 1 a in the $a c, c b$, and $b a$ crystallographic planes.

Table I. Principal Values and Direction Cosines of the $\mathbf{A}(\mathrm{MHz})$ and g Tensors of $1 \mathbf{a}^{a}$

\begin{tabular}{cllrrr}
\hline & & & \multicolumn{3}{c}{ direction cosines } \\
\cline { 4 - 6 } & tensor & & \multicolumn{1}{c}{$a$} & \multicolumn{1}{c}{$b$} & \multicolumn{1}{c}{$c$} \\
\hline${ }^{31} \mathrm{P}$ & $A_{1}$ & 2111 & 0.164 & 0.794 & 0.585 \\
& $A_{2}$ & 2143 & 0.144 & 0.568 & -0.810 \\
& $A_{3}$ & 2575 & -0.976 & 0.217 & -0.022 \\
${ }^{35} \mathrm{Cl}$ & $A_{1}$ & 61 & 0.071 & 0.581 & -0.881 \\
& $A_{2}$ & 69 & 0.431 & -0.751 & -0.500 \\
& $A_{3}$ & 157 & -0.900 & -0.314 & -0.304 \\
$\mathrm{~g}$ & $g_{1}$ & 2.001 & 0.736 & 0.545 & 0.402 \\
& $g_{2}$ & 2.003 & 0.677 & -0.602 & -0.422 \\
& $g_{3}$ & 2.010 & 0.012 & 0.583 & -0.813 \\
\hline
\end{tabular}

${ }^{a}$ The direction cosines are listed for one of the four possible sites. The remaining three orientations are related to $(x, y, z)$ by $(x,-y,-z)$, $(-x,-y, z)$, and $(-x, y,-z)$.

where $\mathrm{A}_{\mathrm{P}}$ and $\mathrm{A}_{\mathrm{Cl}}$ describe the ${ }^{31} \mathrm{P}$ and ${ }^{35} \mathrm{Cl}$ hyperfine interactions and the remaining symbols have their usual definition. The ${ }^{37} \mathrm{Cl}$ satellite resonances were not always resolved in the spectra, thus hampering the analysis in full detail. The magnetic parameters were optimized to reproduce the experimental field positions via an exact diagonalization of the Hamiltonian. For the final $\mathbf{A}_{P}$, $\mathbf{A}_{\mathrm{Cl}}$, and $\mathbf{g}$ tensors the root mean square error of all observed and calculated field values is $0.25 \mathrm{mT}$, substantially less than the line width.

Table I comprises the $\mathbf{A}_{\mathrm{P}}, \mathbf{A}_{\mathrm{Cl}}$, and $\mathbf{g}$ tensors of radical $\mathbf{1 a}$. The isotropic and dipolar components of the hyperfine coupling tensors can be derived from the three principal values via the equations ${ }^{8}$

$$
\begin{gathered}
A_{\text {iso }}=\left(A_{1}+A_{2}+A_{3}\right) / 3 \\
A_{\text {dip }}=\left(A_{3}-A_{\text {iso }}\right) / 2
\end{gathered}
$$

$A_{\text {iso }}$ and $A_{\text {dip }}$ give a measure of the valence s and p orbital spin densities $\left(\rho_{\mathrm{s}}\right.$ and $\left.\rho_{\mathrm{p}}\right) .^{10}$ For radical $1 \mathrm{a}$ both $\rho_{\mathrm{s}}$ and $\rho_{\mathrm{p}}$ of the central phosphorus atom and the chlorine substituent (Table II) indicate a large unpaired electron density in the $\mathrm{P}-\mathrm{Cl}$ bond. The principal directions of the maximum ${ }^{31} \mathrm{P}$ and ${ }^{35} \mathrm{Cl}$ hyperfine couplings are

(10) Morton, J. R.; Preston, K. F. J. Magn. Reson. 1978, 30, 577. inclined by an angle of $35.3^{\circ}$. Without additional information it is not possible to give a definite correlation between the four molecules in the unit cell and the four sets of magnetic parameters. In principle, four different assignments are possible. Nevertheless, these four assignments are rather similar and lead to the result that the angle of the ${ }^{31} \mathrm{P}-A_{3}$ direction with the $\mathrm{P}-\mathrm{Cl}$ bond of the undamaged molecule lies between 12 and $17^{\circ}$, whereas the corresponding angle for the ${ }^{35} \mathrm{Cl}-A_{3}$ lies between 19 and $33^{\circ}$.

A similar single-crystal analysis for the corresponding phosphoranyl radicals in $\mathbf{2}$ proved to be impracticable because of the small radical concentration. Consequently the magnetic parameters of $2 a$ were obtained from the powder spectrum (Figure $2 b$ ). Due to the low signal intensity and the complicated appearance of the patterns associated with the ${ }^{35} \mathrm{Cl} /{ }^{37} \mathrm{Cl}$ couplings, the principal couplings cannot be determined accurately. Via the parallel $\left(A_{\|}\right)$and perpendicular $\left(A_{\perp}\right)$ components of the ${ }^{31} \mathrm{P}$ and ${ }^{35} \mathrm{Cl}$ couplings, which can be found in the spectrum, the isotropic and dipolar hyperfine interactions can be obtained from the expressions $^{9}$

$$
\begin{aligned}
& A_{\text {iso }}=\left(A_{\|}+2 A_{\perp}\right) / 3 \\
& A_{\text {dip }}=\left(A_{\|}-A_{\text {iso }}\right) / 2
\end{aligned}
$$

The resulting $A_{\text {iso }}, A_{\text {dip }}$, and valence orbital spin densities for $\mathbf{2 a}$ are compiled in Table II.

Table II shows that the magnetic parameters of 1a and $2 \mathbf{a}$ are very similar. The experimental spin density distribution and the directional information of $1 \mathrm{a}$ lead to the conclusion that the extra electron of both 1a and 2a occupies an antibonding $\sigma^{*}$ orbital. In addition, the present hyperfine coupling parameters are in good agreement with previous data on similar $\sigma^{*} \mathrm{P}-\mathrm{Cl}$ configurations. $4,11,12$

Matrix Analysis. The ESR analysis presented above demonstrates that the efficiency of the radiogenic formation of electron-capture phosphoranyl radical products does not solely depend on the nature of the atoms linked to phosphorus. The central

(11) Berclaz, T.; Geoffroy, M.; Lucken, E. A. C. Chem. Phys. Lett. 1975, 35,677 .

(12) Janssen, R. A. J.; Sonnemans, M. H. W.; Buck, H. M. J. Am. Chem. Soc. 1986, 108, 6145 . 
Table II. Isotropic and Dipolar Hyperfine Couplings, $g$ Values, and Approximate Orbital Spin Densities of Phosphorus-Centered Radicals

\begin{tabular}{|c|c|c|c|c|c|c|c|c|c|c|}
\hline \multirow[b]{2}{*}{ radical } & \multirow[b]{2}{*}{$g_{1}$} & \multirow[b]{2}{*}{$g_{\perp}$} & \multicolumn{4}{|c|}{${ }^{31} \mathrm{P}$} & \multicolumn{4}{|c|}{${ }^{35} \mathrm{Cl}$} \\
\hline & & & $A_{\text {iso }}, \mathrm{MHz}$ & $2 A_{\text {dip }}, \mathrm{MHz}$ & $\rho_{\mathrm{s}}, \%$ & $\rho_{\mathrm{p}}, \%$ & $A_{\text {iso }}, \mathrm{MHz}$ & $2 A_{\text {dip }}, \mathrm{MHz}$ & $\rho_{\mathrm{s}}, \%$ & $\rho_{\mathrm{p}}, \%$ \\
\hline $1 \mathrm{a}$ & 2.001 & 2.010 & 2276 & 299 & 17.0 & 40.7 & 95 & 62 & 1.7 & 17.5 \\
\hline 1d & 1.999 & 2.006 & 1350 & 269 & 10.1 & 36.6 & & & & \\
\hline $2 a$ & 1.998 & 2.014 & 2336 & 246 & 17.5 & 33.5 & 93 & 55 & 1.6 & 15.7 \\
\hline $2 b$ & 1.999 & 2.006 & 1385 & 247 & 10.4 & 33.6 & & & & \\
\hline
\end{tabular}

phospholidine moieties of $\mathbf{1}$ and $\mathbf{2}$ are enantiomeric and therefore expected to possess identical electron-accepting properties. According to Bartczak et al. ${ }^{5,6}$ the molecular geometry of $\mathbf{1}$ $(2 R, 4 S, 5 R)$ resembles rather closely that of its diastereoisomer $2(2 S, 4 S, 5 R)$. Their $\mathrm{P}-\mathrm{Cl}$ bond lengths are reported to be almost identical ( 2.047 and $2.049 \AA$ ). Furthermore, both $\mathrm{P}-\mathrm{Cl}$ bonds are in an axial position with respect to the ring defined by the least-squares plane, constituted by $\mathrm{N}, \mathrm{P}, \mathrm{O}$, and $\mathrm{C}(5)$. The angle of the $\mathrm{P}-\mathrm{Cl}$ bond with the normal to the plane for $\mathbf{1}\left(19.1^{\circ}\right)$ is very similar to the corresponding angle for $2\left(26.5^{\circ}\right)$. The geometric equivalence of the phospholidine moieties of $\mathbf{1}$ and $\mathbf{2}$ leads to the tentative conclusion that the intrinsic molecular properties of $\mathbf{1}$ and $\mathbf{2}$ are not likely to cause the pronounced difference in electron-capture yield. We favor an explanation in terms of steric intermolecular interactions, which affect the geometry relaxation accompanying the stabilization of an initially formed $\mathrm{P}-\mathrm{Cl}$ bond electron adduct. In the present case of molecules $\mathbf{1}$ and $\mathbf{2}$, it is expected that the necessary relaxation takes the form of $\mathrm{P}-\mathrm{Cl}$ bond stretching. We therefore studied the steric molecular interactions that result in the single-crystal matrix upon elongation of the $\mathrm{P}-\mathrm{Cl}$ bond.

The precursor molecules $\mathbf{1}$ and $\mathbf{2}$ in their respective crystal lattice and surrounded by their nearest neighbors are depicted in Figure 4. This figure shows that the steric hindrance encountered upon stretching the $\mathrm{P}-\mathrm{Cl}$ bond is less for compound $\mathbf{1}$ than for compound $\mathbf{2}$. A more quantitative determination of the steric interactions involved in $\mathrm{P}-\mathrm{Cl}$ bond elongation and distortion was obtained by expanding the crystal lattice, using the reported crystallographic data around a single central molecule. All nearest neighboring molecules (total of 27 cells, 108 molecules) were included and the steric interaction of the chlorine nucleus was monitored as a function of the $\mathrm{P}-\mathrm{Cl}$ bond length and the orientation of the $\mathrm{P}-\mathrm{Cl}$ vector with respect to the original $\mathrm{P}-\mathrm{Cl}$ bond by calculating the distance between chlorine and each of the surrounding nuclei. Of all distances determined, the shortest steric interaction distance for a particular elongation and orientation was then defined as the distance of the nearest-neighbor interaction whose value is less than the distance of the same interaction in the undeformed crystal. Parts a and b of Figure 5 show the contour plots of the shortest interaction distance obtained for $\mathbf{1}$ and $\mathbf{2}$ for a constant elongation of the $\mathrm{P}-\mathrm{Cl}$ bond to $2.30 \AA$. The contour lines correspond to orientations for which the shortest steric interaction distance has a constant value. The $x$ and $y$ coordinates in these plots represent the projection of the position of the chlorine nucleus on a plane perpendicular to the original $\mathrm{P}-\mathrm{Cl}$ bond. Since the shortest steric interaction distance of $\mathbf{1}$ reaches higher values than its isomer $\mathbf{2}$, it can be concluded that the space available to $\mathbf{1}$ is larger than the space available to 2. These plots and similar ones for other stretching distances show that not only the total area embraced by the isosteric curves is larger for $\mathbf{1}$ than for $\mathbf{2}$, but also the direction in which the elongation can be accommodated is in favor of $\mathbf{1}$. For $\mathbf{1}$ the curves are centered around $x=0$ and $y=0$, i.e., elongation is possible without the need of a distortion of the tetrahedral geometry. For $\mathbf{2}$, on the other hand, some distortion is required to reach the region of lesser steric hindrance.

In a second approach we calculated the change in van der Waals energy associated with $\mathrm{P}-\mathrm{Cl}$ bond length elongation for the chlorine nucleus with all other nuclei in the crystal. ${ }^{13}$ Figure 6

(13) The van der Waals parameters were extracted from the MM2 program: Allinger, N. L.; Yuh, Y. H. QCPE 395. Based on the nonbonded distances in the crystal lattices of $\mathbf{1}$ and $\mathbf{2}$ the van der Waals radii of hydrogen and carbon were shortened to 1.20 and $1.85 \AA$, respectively.
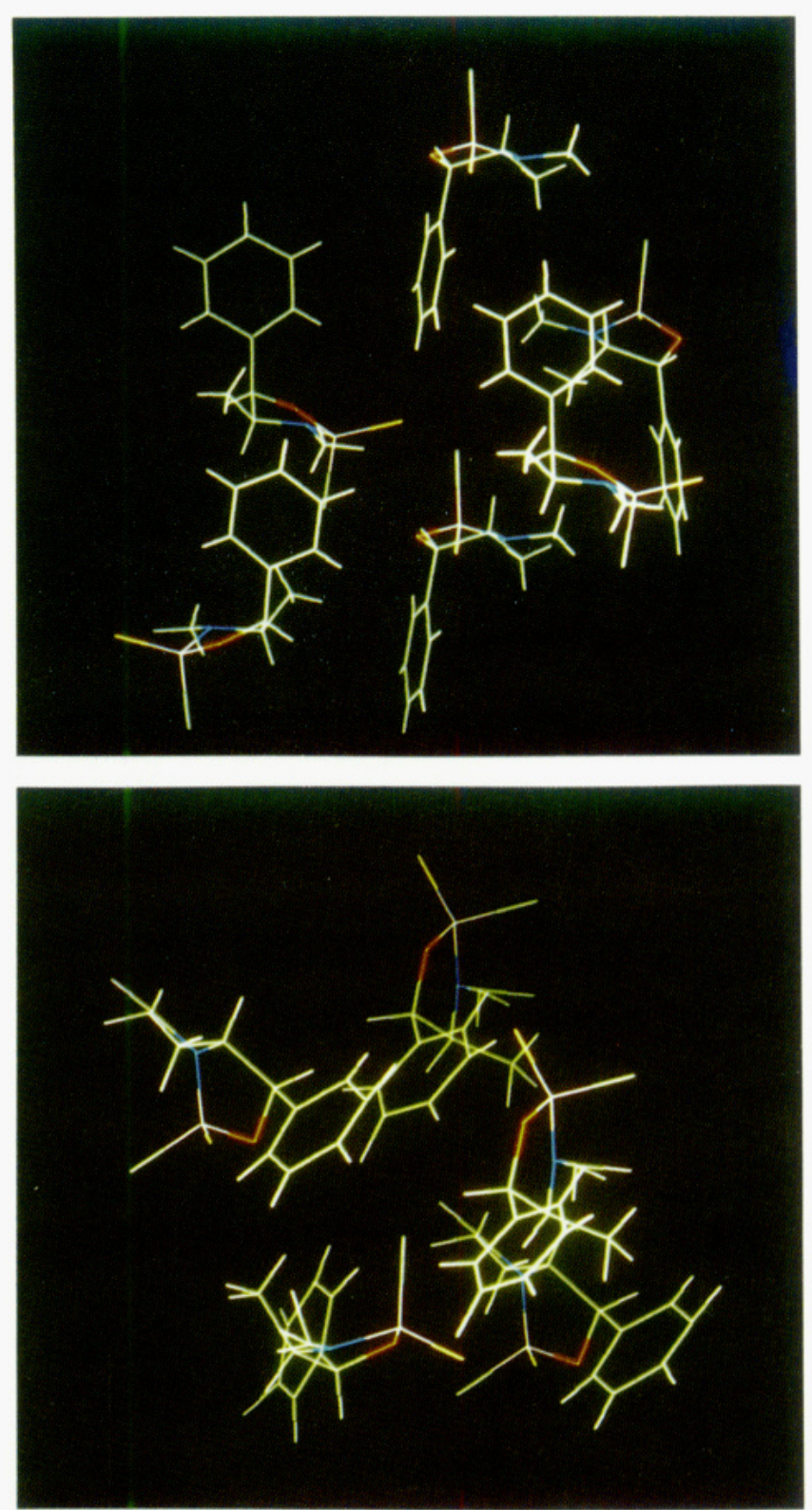

Figure 4. Graphical representation of the precursors 1 (a, top) and $\mathbf{2}$ (b, bottom) in their respective crystal lattice surrounded by the nearest neighboring molecules. The precursors are located at the bottom of the picture, with the $\mathrm{P}-\mathrm{Cl}$ bond directed upwards.

shows the contour plots of the change in van der Waals energy for $\mathbf{1}$ and $\mathbf{2}$ for an elongation from 2.05 to $2.30 \AA$. The plots are rather similar to Figure 5 and give some insight into the energy required for the distortions.

Figures 5 and 6 demonstrate that a change of the Cl-P-S angle (corresponding to the $x$ coordinate in the plot) is a low-energy distortion for $\mathbf{1}$ but severely hindered in $\mathbf{2}$. The importance of this distortion appears from previous studies on similar $\mathrm{P}-\mathrm{Cl} \sigma^{*}$ phosphoranyl radicals, which have shown that the singly occupied molecular orbital (SOMO) is located in the plane of phosphorus, chlorine, and the doubly bonded substituent ${ }^{4,12}$ (in the present case the sulfur atom). This is the result of some admixture of a trigonal-bipyramidal (TBP) configuration with the unpaired 

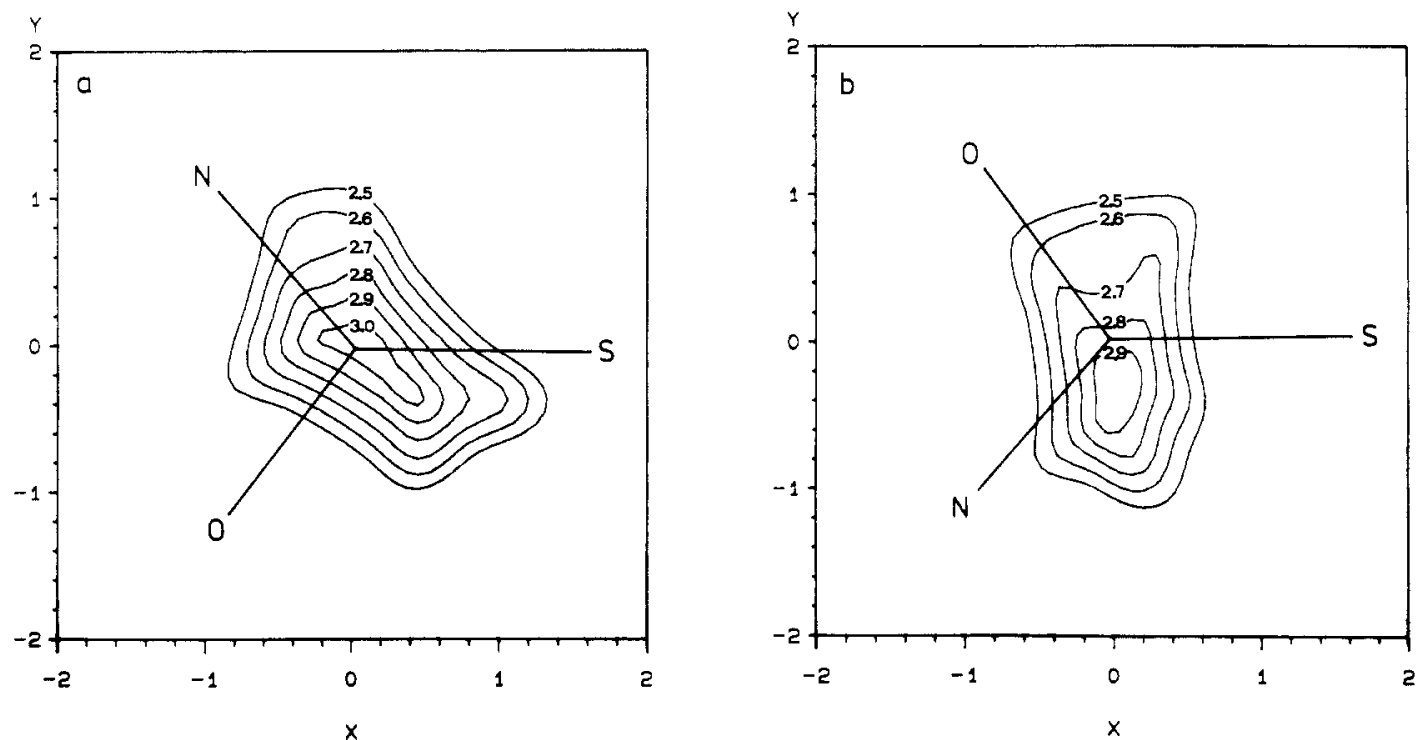

Figure 5. Contour plots of the shortest steric interaction distance $(\AA)$ encountered upon elongation of the $\mathrm{P}-\mathrm{Cl}$ bond to $2.30 \AA$ ( $x$ and $y$ coordinates are in $\AA$ ) (see text): (a) $2 R, 4 S, 5 R$ isomer 1; (b) $2 S, 4 S, 5 R$ isomer 2 .
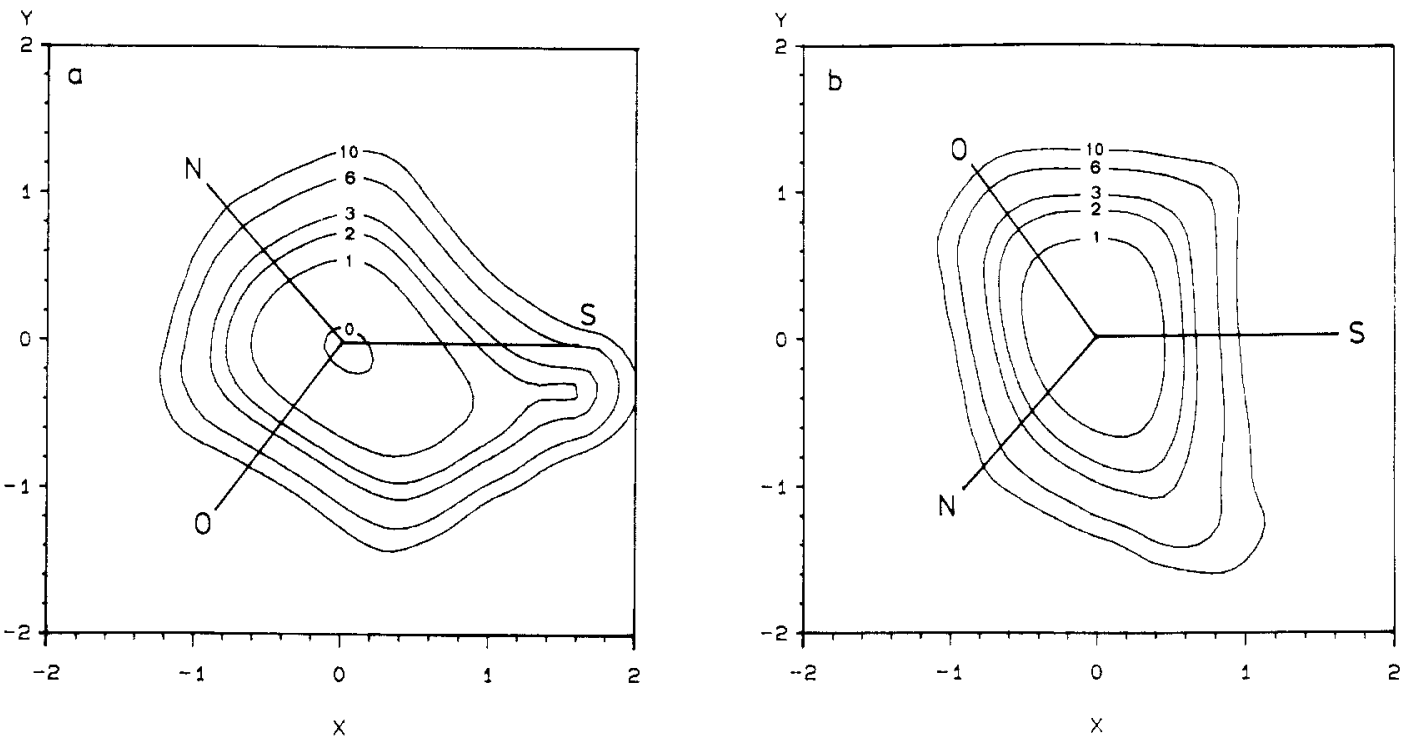

Figure 6. Contour plots of the change in van der Waals energy $(\mathrm{kcal} / \mathrm{mol})$ of the chlorine nucleus in the single crystal upon elongation of the $\mathrm{P}-\mathrm{Cl}$ bond from 2.05 to $2.30 \AA$ ( $x$ and $y$ coordinates are in $\AA$ ) (see text):

(a) $2 R, 4 S, 5 R$ isomer 1 ; (b) $2 S, 4 S, 5 R$ isomer 2 .

electron in an equatorial position (TBP-e) to the $\sigma^{*}$ configuration. ${ }^{14,15}$ As a consequence, the geometric and electronic configuration of the phosphoranyl radical is distorted to some extend from an exact $\sigma^{*}$ toward a TBP-e structure. The single-crystal ESR experiments on 1a demonstrate that the angle of the ${ }^{31} \mathrm{P}-A_{3}$ direction with the original $\mathrm{P}-\mathrm{Cl}$ bond lies between 12 and $17^{\circ}$ (vide supra). Since the ${ }^{31} \mathrm{P}-A_{3}$ direction corresponds to the direction of the phosphorus $3 \mathrm{p}$ atomic orbital contributing to the SOMO, the SOMO is distorted by the same amount from the parent $\mathrm{P}-\mathrm{Cl}$ bond. For ${ }^{35} \mathrm{Cl}$, the corresponding angle is even larger $\left(19-33^{\circ}\right)$, but this has a smaller effect because the atomic spin density on chlorine (19.2\%) is much less than on phosphorus. The important effect of the distortion of the SOMO from the parent

(14) Hasegawa, A.; Ohnishi, K.; Sogabe, K.; Miura, M. Mol. Phys. 1975, 30,1367 .

(15) Howell, J. M.; Olsen, K. F. J. Am. Chem. Soc. 1976, 98, 7119.

(16) Symons, M. C. R.; Petersen, R. L. J. Chem. Soc., Faraday Trans. 21979,210

(17) Cooper, J. W.; Parott, M. J.; Roberts, B. P. J. Chem. Soc., Perkin Trans. $21977,730$.

(18) Griller, D.: Roberts, B. P., J. Chem. Soc., Perkin Trans. 2 1973, 1416

(19) Mishra, S. P.; Symons, M. C. R. J. Chem. Soc., Dalton Trans. 1976. 1622.
$\mathrm{P}-\mathrm{Cl}$ bond is in fact 2-fold; first the $\mathrm{Cl}-\mathrm{P}-\mathrm{S}$ angle widens, and second, the electron density in the plane between the two bonds is increased. Both factors require appreciable space in the $x$ direction, which is available in 1 but not in 2 . From the analysis presented above it is clear that the $\mathrm{P}-\mathrm{Cl}$ bond length elongation and distortion is easily accommodated in 1, but inhibited by nonbonded interactions in $\mathbf{2}$. This explains the observed difference in the yield of electron-capture radicals in the two diastereoisomers.

Radical Formation in a Host Matrix. If the surrounding molecules exert a large effect on the stabilization of phosphoranyl electron-capture radicals, it is to be expected that stabilization can be influenced by changing the microenvironment. This is easily achieved by studying compounds $\mathbf{1}$ and $\mathbf{2}$ in a host matrix, e.g., a frozen organic solvent. Equimolar solutions of $\mathbf{1}$ and $\mathbf{2}$ in 2-methyltetrahydrofuran (MeTHF) were rapidly frozen to form a glassy sample and subsequently X-irradiated for $6 \mathrm{~h}$ at $77 \mathrm{~K}$. Inspection of the resulting spectra at $105 \mathrm{~K}$ (Figure 7) reveals that in MeTHF compounds $\mathbf{1}$ and $\mathbf{2}$ behave very similarly toward $\mathrm{X}$-irradiation. If we confine to the lateral regions of the spectra, two different radical species can be detected for both $\mathbf{1}$ and 2 . There is no doubt that these are both phosphorus-centered radicals. The outer signals, which are broad transitions without any resolvable hyperfine splitting, correspond to the primary electron- 


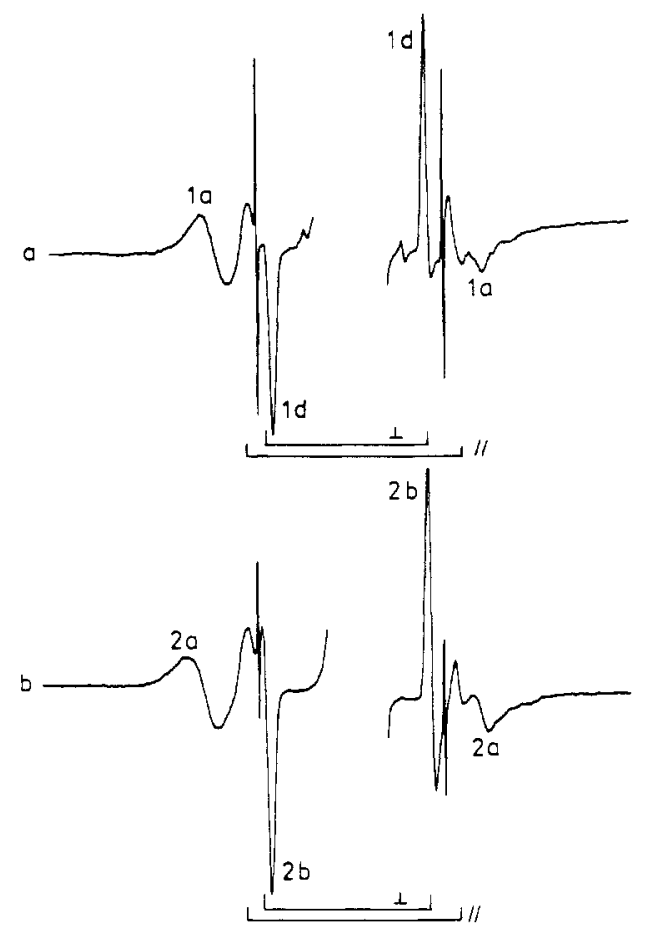

$10 \mathrm{mT}$

Figure 7. ESR spectra in MeTHF host matrix at $105 \mathrm{~K}$ : (a) $2 R, 4 S, 5 R$ isomer 1; (b) $2 S, 4 S, 5 R$ isomer 2 . The parallel (\|) and perpendicular $(\perp)$ transitions are given in the stick diagrams. The central parts of the spectra, which display strong absorptions resulting from radicals and trapped electrons in the $\mathrm{X}$-irradiated quartz tube and frozen solvent, are omitted for clarity.

capture products of the parent molecules $1 \mathbf{a}$ and $2 \mathbf{a}$. The strong features labeled 1d (Figure $7 \mathbf{a}$ ) and $\mathbf{2 b}$ (Figure $7 \mathrm{~b}$ ) are assigned to a thiophosphonyl radical, formed as a result of a dissociation of the $\mathrm{P}-\mathrm{Cl}$ bond. The hyperfine coupling parameters of $1 \mathrm{~d}$ and 2b (Table II) are comparable to those of the thiophosphonyl radical $\left(A_{\text {iso }}=1153 \mathrm{MHz}, 2 A_{\mathrm{dip}}=299 \mathrm{MHz}\right.$ ), formed in single crystals of dipyrrolidinochlorophosphine sulfide after annealing of the primary $\mathrm{P}-\mathrm{Cl} \sigma^{*}$ electron-capture radical product. ${ }^{12}$

This assignment is supported by the increase of the intensity of the signals ascribed to $\mathbf{1 d}$ and $\mathbf{2} \mathbf{b}$ and the concurrent decay of the electron-capture radicals upon raising the temperature to 115 K. Besides the MeTHF matrix, we also examined radical formation in a frozen solution of diethyl ether. It is found that both 1 and 2 almost exclusively give rise to a dissociative electroncapture reaction, giving the thiophosphonyl species $\mathbf{1 d}$ and $\mathbf{2 b}$.

The differences observed between $\mathrm{X}$-irradiation of the pure crystalline compounds and those embedded in a host matrix show

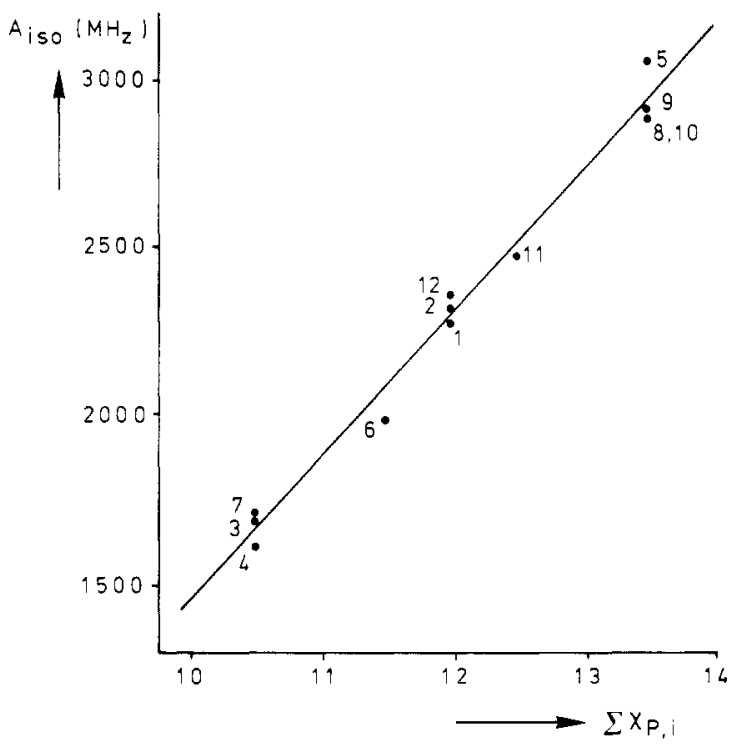

Figure 8. The isotropic ${ }^{31} \mathrm{P}$ hyperfine coupling constant $A_{\text {iso }}(\mathrm{MHz})$ vs the sum of the Pauling electronegativities of the four atoms linked to phosphorus for a number of $\mathrm{P}-\mathrm{Cl} \sigma^{*}$ phosphoranyl radical configurations known from literature data. $(1,1 \mathrm{a} ; 2,2 \mathrm{a} ; 3$, ref $11 ; 4$, ref $16 ; 5$, ref 4 ; 6 , ref $12 ; 7$, ref $16 ; 8$, ref $17 ; 9$, ref $17 ; 10$, ref $18 ; 11$, ref $17 ; 12$, ref 19 ).

unequivocally that the stabilization of radiogenic radical products is controlled by the environment of its precursor.

\section{Discussion}

The present study demonstrates that the efficiency of the radiogenic formation of electron-capture radical products strongly depends on steric interactions with surrounding molecules. The high yield of phosphoranyl radicals in crystals of 1 is a consequence of the space that is available for the elongation of the P-Cl bond after electron capture. For 2, nonbonded interactions in the crystal matrix prevent the elongation and distortion of the $\mathrm{P}-\mathrm{Cl}$ bond and hence almost no phosphoranyl radicals are formed. The experiments in a MeTHF and diethyl ether host matrix demonstrate that when both diastereoisomers possess a similar environment, they react in almost the same way.

The strong effect of the matrix on radical stabilization raises the question whether the electronic configuration and especially the spin density distribution are also affected by matrix effects. To address this question we have made a plot (Figure 8 ) of the isotropic phosphorus hyperfine coupling constant $\left(A_{\text {iso }}\right)$ vs the sum of the Pauling electronegativities $\left(\sum \chi_{\mathrm{P}, \mathrm{j}}\right.$ ) of the four atoms directly linked to phosphorus for a number of $\sigma^{*} \mathrm{P}-\mathrm{Cl}$ phosphoranyl radicals, known from literature data on both solid- and liquid-state ESR experiments. It is found that there exists a linear relationship between $A_{\text {iso }}$ and $\sum \chi_{\mathrm{P}, j}$. This unambiguously demonstrates that the spin density distribution is primarily a consequence of intrinsic

\section{Scheme I}
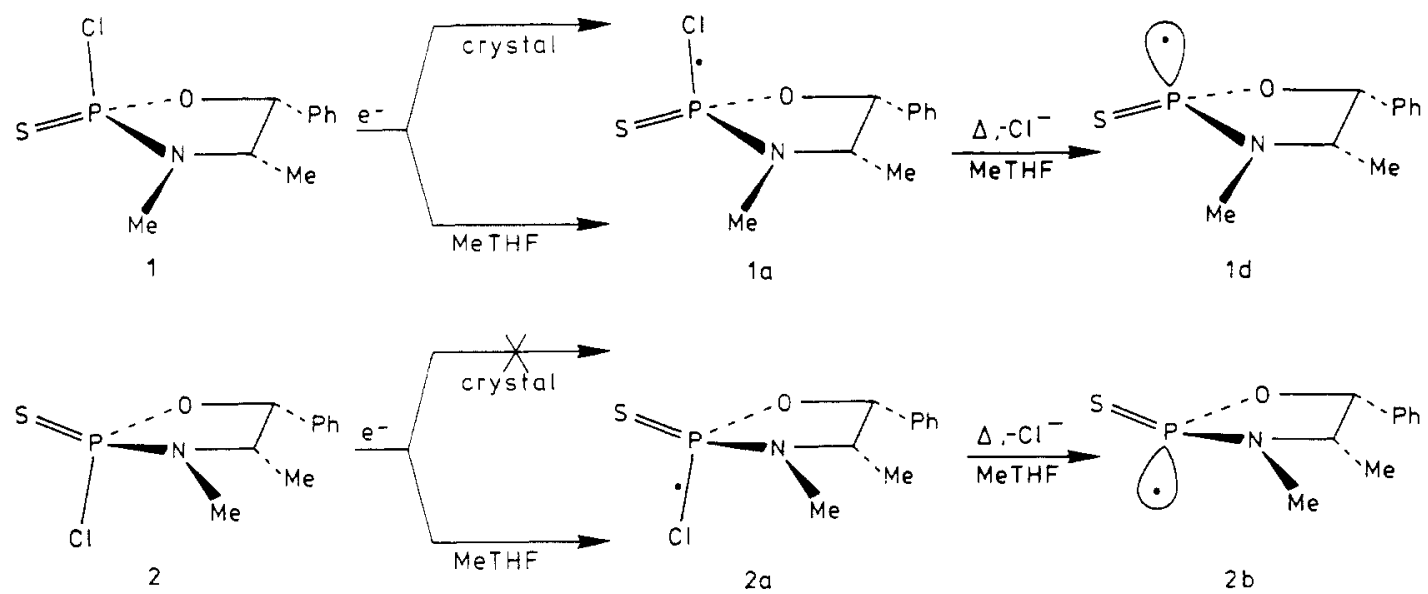


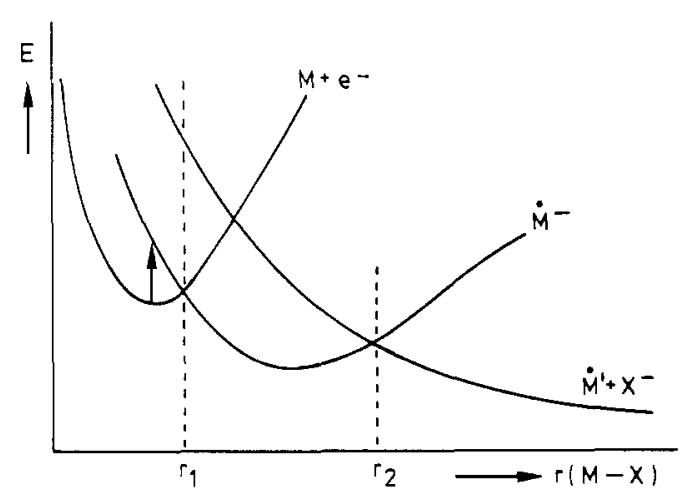

Figure 9. Schematic energy diagram for electron capture in a $M-X$ bond as function of the $\mathrm{M}-\mathrm{X}$ distance $(r(\mathrm{M}-\mathrm{X}))$. Energy curves are given for the neutral molecule, the radical anion, and the dissociative process. The arrow indicates the initial electron addition.

molecular properties and not of intermolecular interactions with the environment of the radical. It is interesting to note that the positive slope of the line depicted in Figure 8 reflects the antibonding character of the SOMO, i.e., $A_{\text {iso }}$, and thus the spin density on phosphorus increases when the surrounding substituents become more electronegative.

There remains an important difference between the singlecrystal and host matrix experiments. In the single crystals of 1 the main radical product is the electron-capture species $1 \mathrm{a}$, whereas in MeTHF or diethyl ether the dissociation product 1d dominates. In addition, the thermal stability of $1 \mathbf{a}$ in the crystal is considerably higher than in the frozen matrix, i.e., la can be detected in the crystal for temperatures up to $225 \mathrm{~K}$ but a slight warming of the MeTHF matrix to $115 \mathrm{~K}$ results directly in the dissociation of 1a into 1d. Again, this effect can be attributed to steric interactions. The host matrix apparently provides sufficient space to allow a dissociation, whereas the same process in the crystal is hampered by neighboring molecules.

Figure 9 gives a schematic plot of the energy curves involved in the electron-capture and dissociative processes of 1 and 2 . Three different potential hypersurfaces are of importance in this respect: (i) the surface that describes the original precursor molecule $M$, (ii) the electron-capture radical surface $\mathrm{M}^{\bullet-}$, and (iii) the dissociative surface describing $\mathrm{M}^{* \prime}$ and $\mathrm{X}^{-}$. As can be seen from Figure 9 two characteristic distances $\left(r_{1}\right.$ and $\left.r_{2}\right)$ of the $\mathrm{M}-\mathrm{X}$ bond exist. If the matrix restricts the geometry relaxation to a value below $r_{1}$, no radical anions will be formed. This probably occurs in the pure $2 S, 4 S, 5 R$ compound 2 . If, however, the limit lies above $r_{1}$ but below $r_{2}$, an electron-capture radical can be readily formed and will be stable toward dissociation because of the steric interactions encountered at $r=r_{2}$ (radical 1a in the single-crystal matrix). Finally, when there exists no steric hindrance below $r_{2}$, a dissociation can occur provided the intrinsic energy barrier at $r_{2}$ can be reached at the temperature at which the experiment is performed. Since a three-electron $\mathrm{P}-\mathrm{Cl} \sigma^{*}$ bond is expected to be rather weak, the force constant associated with the $\mathrm{P}-\mathrm{Cl}$ bond vibration is low and the curve of $\mathrm{M}^{--}$will possess only a shallow minimum. As a consequence it can be expected that all molecular arrangements between $r_{1}$ and $r_{2}$ possess a similar spin density distribution.

In this respect it is important to note that the mode of geometry relaxation, necessary for the stabilization of a particular electron-capture radical, first of all depends on the intrinsic properties of the precursor molecule. In general this relaxation will take the form of bond stretching or bond bending. In special cases, more than one deformation will be possible for stabilization, leading to different radical configurations. ${ }^{20}$ The actual relaxation process is expected to be an energetically favorable combination of intrinsic stabilization modes and external intermolecular constraints imposed upon the molecule by its environment. This leads to the principle that in general an electron-capture radical product can only be generated when the space offered by the matrix corresponds to a favorable relaxation pathway of a hypothetical isolated molecule. The important result is that the electron-accepting properties of a molecule will only be fully expressed if the matrix easily accommodates the newly formed radical product. Nevertheless, the resulting radical structure corresponds to a low-energy configuration of the isolated molecule.

Acknowledgment. This investigation has been supported by the Netherlands Foundation for Chemical Research (SON) with financial aid from the Netherlands Organization for Scientific Research (NWO). Dr. Aart A. van Beuzekom (Unilever Research, Vlaardingen, The Netherlands) is gratefully acknowledged for the use and services of molecular modeling facilities. We thank Mr. Lars Evers and Mr. Frank Cammaert for assistance in parts of this work.

(20) Janssen, R. A. J.; Sonnemans, M. H. W.; Buck, H. M. J. Chem. Phys. 1986, 84,3694 